\title{
DESEMPENHO E RETENÇÃO DE NITROGÊNIO DE FRANGOS DE CORTE DOS 22 AOS 42 DIAS ALIMENTADOS COM RAÇÕES COM DIFERENTES NÍVEIS DE CÁLCIO E SUPLEMENTADAS COM FITASE
}

\begin{abstract}
RESUMO - Com o objetivo de avaliar os níveis de cálcio na ração suplementada com enzima fitase para frangos de corte de 22 a 42 dias de idade, foi conduzido um experimento com 600 frangos de 21 dias da linhagem Hubbard-MPK, distribuídos em um delineamento inteiramente casualizado, em arranjo fatorial cinco $\mathrm{x}$ dois (níveis de cálcio da dieta $\mathrm{x}$ sexos), com três repetições de 20 aves por parcela. A ração basal foi balanceada para atender às exigências nutricionais das aves, conforme o NRC (1994), exceto para o cálcio, cujos níveis foram 0,$40 ; 0,59 ; 0,78 ; 0,97$ e 1,16\%, suplementada com Fitase. Aos 35 dias de idade, duas aves de cada tratamento foram transferidas para gaiolas de metabolismo para coleta total das excretas durante quatro dias. O consumo
\end{abstract}

\author{
ANTÔNIO SOARES TEIXEIRA ${ }^{1}$ \\ NEUDI ARTEMIO SCHOULTEN ${ }^{2}$ \\ HUNALDO OLIVEIRA SILVA ${ }^{3}$ \\ ADEMIR JOSÉ CONTE \\ ANTÔNIO GILBERTO BERTECHINI ${ }^{5}$ \\ ANTONIO GILBERTO BERTECHINI
ELIAS TADEU FIALHO
}

TERMOS PARA INDEXAÇÃO: Digestibilidade, desempenho, exigência, fósforo.

\section{PERFORMANCE AND NITROGEN RETENTION IN BROILERS FROM 22 TO 42 DAYS OLD FED DIETS WITH DIFFERENT LEVELS IN CALCIUM SUPPLEMENT WITH FITASE}

\begin{abstract}
With the objective of evaluating the levels of calcium in the ration supplemented with phytase for broiler chickens from 22 to 42 days old, one experiment was conducted by using a total of 600 chickens of 22 days old Hubardb-MPK strain, distributed in a completely randomized design, in five two factorial arrangement (levels of calcium of the diet $\mathrm{x}$ sexes), with three replicates of 20 birds per plot. The
\end{abstract}

de ração e o ganho de peso foram de 12,8 e $16 \%$ respectivamente, e superiores $(\mathrm{P}<0,01)$ para os machos. Não houve diferença $(\mathrm{P}>0,05)$ para o consumo de ração, ganho de peso e conversão alimentar em razão dos níveis crescentes de cálcio nas rações. A digestibilidade da matéria seca foi melhor com o nível de $0,88 \%$ de cálcio, e a maior retenção de nitrogênio foi obtida com $0,70 \%$ de cálcio na ração suplementadas com fitase. Conclui-se que o aumento dos níveis de cálcio em rações suplementadas com fitase para frangos de corte dos 22 aos 42 dias de idade não afeta o desempenho dos mesmos, e níveis muito baixos de cálcio reduzem a digestibilidade da matéria seca e retenção de nitrogênio das rações.

1. Engenheiro Agrônomo, D.Sc., Professor do Departamento de Zootecnia da UNIVERSIDADE FEDERAL DE LAVRAS/UFLA, Caixa Postal 37, 37200-000 - Lavras, MG.

2. Lic. Cienc. Agr., M.Sc., Professor Escola Agrotécnica Federal de Rio do Sul - SC, neudi@navinet,com.br

3. Médico Veterinário, M.Sc., Estudante de Doutorado, DZO/UFLA. hunaldo@ufla.br

4. Lic. Cienc. Agr., D.Sc., Professor Escola Agrotécnica Federal de Cuiabá - MT, ajconte@zaz.com.br

5. Zootecnista, D.Sc., Professor do Departamento de Zootecnia/UFLA. 
for the males $(\mathrm{P}<0.01)$ in relation to the females, respectively. There was no differences for feed intake, weight gain and feed conversion in relation to the levels of calcium in the diets $(\mathrm{P}>0.05)$ supplemented with phytase. The digestibility of dry matter was better with $0.88 \%$ of calcium in the diets and the higher nitrogen retention, was obtained with $0.70 \%$ of calcium. It was possible to conclude that the increasing levels of calcium in diets supplemented with phyitase for broilers from 22 to 42 days old did not influenced the broiler performance and also shown that very low levels of calcium in the diets impaired the digestibility of the dry matter and nitrogen retention.

INDEX TERMS: Digestibility, phosphorus, performance, requirement.

\section{INTRODUÇÃO}

A ração de frangos de corte é baseada em alimentos de origem vegetal, os quais, segundo Rostagno (1998), apresentam de 45 a $75 \%$ de seu fósforo indisponível para animais monogástricos, porque esse elemento está complexado à molécula do fitato. A molécula do fitato, além do fósforo, contém em sua constituição outros minerais, mono e divalentes, como o cálcio, zinco, cobre, ferro, potássio, magnésio e manganês. Segundo Sebastian et al. (1996), a utilização da fitase não só reduz a necessidade de suplementação com fósforo, mas também a de outros minerais que podem ser liberados para a absorção. O efeito da fitase sobre a disponibilidade do fósforo já é bastante estudado e relativamente bem estabelecido (Borges, 1997), o que não ocorre com os outros minerais complexados com o fitato. Sendo assim, torna-se necessária a avaliação da suplementação desses minerais em rações suplementadas com fitase, principalmente do cálcio, que sofre efeito negativo na sua disponibilidade quando na presença de ácido fítico. Por outro lado, conforme Leske \& Coon (1999), o nível de cálcio da dieta afeta a disponibilidade de outros minerais da dieta, principalmente do fósforo fítico, o que foi verificado por Simons et al. (1990) em experimento com frangos de corte, em que foi testada uma dieta variando o cálcio de 0,6 a $0,9 \%$, no qual observou-se decréscimo da porcentagem de retenção de fósforo conforme o teor de cálcio da dieta foi elevado. Embora normalmente não haja preocupação dos nutricionistas com o excesso de cálcio na ração em virtude do seu baixo custo e por não apresentar toxicidade, Shafey (1993) cita que diversos trabalhos de pesquisa demonstram depressão do ganho de peso e redução da eficiência alimentar em aves que receberam ração contendo níveis de cálcio variando de 1,3 a 1,7\%. Segundo Shafey (1993), a redução de desempenho de frangos em função de níveis elevados de cálcio é aparente na literatura, embora ainda haja discordância em relação aos níveis máximos tolerados, e 1,2\% de cálcio já provoca redução no ganho de peso. Conforme Karunajeewa (1976), quando as fontes de minerais são altamente disponíveis, $0,6 \% \%$ de cálcio e $0,57 \%$ de fósforo na dieta são suficientes para proporcionar adequada taxa de crescimento e mineralização óssea para frangos em crescimento. Em estudo de dieta suplementada com fitase para frangos de corte, Sebastian et al. (1997) verificaram que $0,58 \%$ de cálcio e $0,44 \%$ de fósforo total na dieta proporcionaram melhores resultados de digestibilidade de aminoácidos e desempenho superior quando comparado à dieta contendo nível normal de cálcio e fósforo $(0,95 \%$ e $0,63 \%$, respectivamente) e também foi melhor do que a dieta contendo nível normal de cálcio $(1,05 \%)$ e baixo fósforo total $(0,48 \%)$. O efeito adverso de níveis de cálcio elevados sobre o desempenho de frangos na fase inicial de criação é bastante vasto na literatura, porém, para as fases seguintes, praticamente não há pesquisa a respeito do assunto. Portanto, o objetivo com este trabalho foi determinar o efeito dos níveis de cálcio da ração suplementada com fitase sobre o desempenho e digestibilidade da matéria seca e retenção de nitrogênio em frangos de corte de 22 a 42 dias de idade.

\section{MATERIAL E MÉTODOS}

O experimento foi realizado no Setor de Avicultura da Escola Agrotécnica Federal de Cuiabá (MT), em janeiro e fevereiro de 2000. Foram utilizados 600 frangos de corte de 21dias, da marca Hubbard-MPK, no período 22 a 42 dias, alojados em galpão sobre cama, distribuídos em cinco tratamentos e seis repetições, sendo três de cada sexo. Os tratamentos foram dispostos em um delineamento inteiramente casualizado, em esquema fatorial cinco x dois, sendo cinco níveis de cálcio na ração $(0,40$; 0,$59 ; 0,78 ; 0,97$ e $1,16 \%$ ), obtidos pela substituição do caulim da dieta basal por calcário, e dois sexos. 
As dietas foram isonutritivas, à base de milho e farelo de soja, com $0,43 \%$ de fósforo total, suplementadas com 600 unidades de fitase $/ \mathrm{kg}$, formuladas para atender às exigências nutricionais, conforme recomendado pelo NRC (1994), exceto para o cálcio, sendo a composição dos ingredientes obtida de Rostagno et al. (1994). A disponibilidade do P de origem vegetal foi considerada como sendo de dois terços, tendo em vista a suplementação com fitase. A enzima utilizada no experimento foi a NATUPHOS 5000, fornecida pela BASF, obtida por fermentação por meio de fungos (Aspergillus niger), com atividade mínima declarada pelo fornecedor de $5000 \mathrm{FTU} / \mathrm{g}$. A composição da ração basal pode ser observada na Tabela 1. Ração e água foram fornecidas à vontade e mantido um programa de 24 horas de luz, visando a estimular o consumo de ração nas horas mais frescas do dia, uma vez que a temperatura diurna nessa época do ano é bastante elevada. Para a digestibilidade da matéria seca da ração e retenção de nitrogênio, duas aves de cada parcela foram alojadas em gaiolas de metabolismo para coleta total de excretas, no período de 39 a 42 dias de idade. A estimativa da excreção endógena e metabólica de ma- téria seca e nitrogênio para o cálculo da digestibilidade verdadeira da matéria seca e da retenção verdadeira de nitrogênio foi obtida mediante a coleta total de excretas de duas aves por parcela, durante 48 horas, após jejum de ração de 24 horas. O material coletado foi acondicionado em sacos plásticos, pesado e armazenado em congelador até o final do período de coleta. No final do período de coleta, as excretas foram descongeladas, devidamente reunidas por repetição, homogeneizadas e retiradas alíquotas de 300 a $400 \mathrm{~g}$ para secagem em estufas ventiladas a $58^{\circ} \mathrm{C}$, por 72 horas, quando, então, foram moídas e acondicionadas para posteriores análises. Com o objetivo de calcular a digestibilidade verdadeira da matéria seca, a retenção verdadeira de nitrogênio e a taxa de absorção real dos minerais em estudo, foi realizada a coleta das excretas durante 48 horas em duas aves por parcela experimental, e submetidas ao jejum de 24 horas para a determinação da excreção endógena de nutrientes. A retenção de nitrogênio e digestibilidade da matéria seca da ração foram calculadas pela seguinte fórmula geral:

$$
\mathrm{AN}=\frac{(\mathrm{IR} \times \mathrm{NR} / 100)-[(\mathrm{E} \times \mathrm{NE} / 100)-(\mathrm{EE} \times \mathrm{NEE} / 100)]}{(\mathrm{IR} \times \mathrm{NR} / 100)} \times 100=\%
$$

Em que:

AN - Absorção do nutriente (\%);

IR - Ingestão de ração/ave/dia (g);

NR - Nutriente na ração (\%);

E - Excretas/ave/dia (g);

NE - Nutriente nas excretas $(\%)$

$\mathrm{EE}$ - Excretas endógenas/dia/ave (g);

NEE - Nutriente nas excretas endógenas (\%).

Ingredientes, rações e excretas foram analisados no Laboratório de Pesquisa Animal do DZO/UFLA, segundo metodologia da AOAC (1990). As análises estatísticas dos resultados obtidos foram realizadas utilizando o programa SISVAR 4.1 (Sistema para Análises de variância de dados balanceados), desenvolvido por Ferreira (2000). As estimativas de exigências de cálcio foram feitas mediante o uso dos modelos de regressão linear, quadrática e Linear Response Plateau (LRP), descrito por Braga (1983), conforme o ajustamento dos dados obtidos para cada variável, interpretando-se as respostas biológicas das aves. As equações do modelo LRP foram obtidas pelo pacote computacional SAEG (Euclydes, 1993). O ajustamento do modelo foi verificado pela soma de quadrados dos desvios, sendo escolhido aquele que apresentou a menor soma de quadrados de desvios.

\section{RESULTADOS E DISCUSSÃO}

As médias de temperaturas e a amplitude térmica registrada durante o período experimental constam na Figura 1. As temperaturas mínimas e máximas registradas no interior do galpão foram de 19,6 e $30,4^{\circ} \mathrm{C}$, respectivamente.

Os valores médios do consumo de ração, ganho de peso, conversão alimentar, taxa de digestibilidade verdadeira da matéria seca da ração e taxa retenção verdadeira de nitrogênio são apresentados na Tabela 2. 
TABELA 1 - Composição da dieta basal.

\begin{tabular}{lc}
\hline \multicolumn{1}{c}{ Ingrediente } & Quantidade (kg) \\
\hline Milho & 645,18 \\
Farelo de soja & 294,51 \\
Óleo de soja & 13,51 \\
Calcário calcítico & 7,46 \\
Monoamônio fosfato & 4,22 \\
Sal & 3,00 \\
Premix mineral & 0,50 \\
Premix vitamínico & 4,00 \\
Fitase & 0,12 \\
Caulim & 27,50 \\
\hline Composição calculada & \\
\hline Energia metabolizável (Kcal /kg) & 3000 \\
Proteína bruta (\%) & 19,00 \\
Cálcio (\%) & 0,40 \\
Fósforo disponível (\%) & 0,32 \\
Metionina (\%) & 0,40 \\
Metionina + Cistina (\%) & 0,71 \\
Lisina (\%) & 0,98 \\
Triptofano (\%) & 0,23 \\
Treonina (\%) & 0,74 \\
\hline O premix forneceu por kg de ração: vitt $\mathbf{A}$
\end{tabular}

O premix forneceu por kg de ração: vit. $A$ - 7.000 UI; vit. $D_{3}-1,500 \mathrm{UI}$; vit. $\mathrm{E}-12 \mathrm{UI}$; vit. $\mathrm{K}-1,5 \mathrm{mg}$; Vit. $B_{1}-1,6$ mg; vit. $B_{2} 5$ mg; vit. $B_{6} 2,6$ mg; vit. $B_{12} 10 \mu g$; Niacina - 35 mg; Ác. Fólico - 0,7 mg; Ác. Pantotênico - 13 mg; Se - 0,3 mg; Colina - 300 mg; Metionina - 1,0 g; Agente anticoccidiano - 0,06 g; Promotor de crescimento - 0,04 g; Antioxidante - 0,02 g; Mn - 75 mg; Zn $-50 \mathrm{mg}$; $\mathrm{Cu}-8 \mathrm{mg}$; I-0,75 mg; $\mathrm{Fe}-50 \mathrm{mg}$.

Em nenhuma variável houve interação $(\mathrm{P}>0,05)$ entre os níveis de cálcio e sexo. Os machos tiveram maior consumo de ração $(\mathrm{P}<0,05)$ e ganho de peso $(\mathrm{P}<0,01)$ do que as fêmeas $(12,8$ e $16,0 \%$, respectivamente); resultados semelhante aos encontrados por Cabral (1999). O maior ganho de peso dos machos pode ser explicado pelo efeito ativador da testosterona sobre a síntese de RNA-polimerase, conforme citado por Teixeira (1994), que favorece o crescimento ósseo e o desenvolvimento da musculatura. Não houve efeito dos níveis de cálcio sobre o consumo de ração, ganho de peso e conversão alimentar ( $\mathrm{P}>0,05)$. Skinner et al. (1992) e Cabral (1999) também não encontraram diferenças significativas para dados de desempenho quando utilizaram diferentes níveis de cálcio para frangos de 22 a 42 dias. Não foi verificada diferença entre os sexos para a digestibilidade da matéria seca da ração e para a taxa de retenção de nitrogênio $(\mathrm{P}>0,05)$. Já os baixos níveis de cálcio reduziram a digestibilidade da matéria seca da ração e a taxa de retenção de nitrogênio $(\mathrm{P}<0,05)$, como pode ser observado nas Figuras 2 e 3, respectivamente.

O nível de $0,46 \%$ de cálcio na ração foi o que afetou de forma mais severa a digestibilidade e retenção de nitrogênio, ao passo que o nível de $0,88 \%$ foi suficiente para atingir a digestibilidade máxima da matéria seca da ração, estimada em $76,79 \%$, e o nível de $0,70 \%$ foi suficiente para maximizar a retenção de nitrogênio da ração, com $80,6 \%$, segundo a estimativa obtida pelo modelo Linear Response Plateu (LRP). Rostagno et al. (2000), embora trabalhando com frangos mais jovens (dez a 19 dias de idade), também verificaram redução na digestibilidade da matéria seca e a retenção de nitrogênio com a elevação do nível de cálcio na dieta.

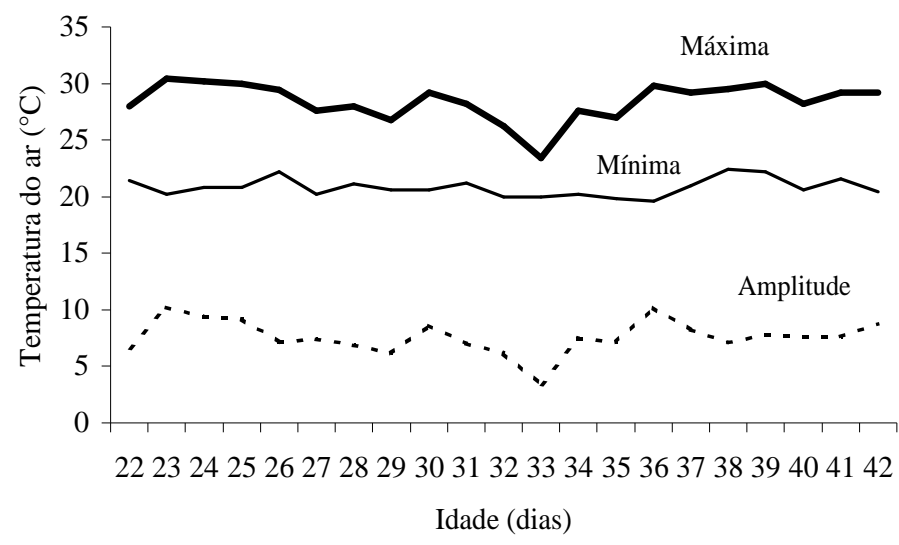

FIGURA 1 - Temperatura máxima, mínima e amplitude térmica registradas na Estação Meteorológica da EAFCMT, no período de 17/01/00 a 07/02/00. 
TABELA 2 - Consumo de ração, ganho de peso, conversão alimentar dos frangos de 22 a 42 dias de idade, taxa de digestibilidade da matéria seca e taxa de retenção de nitrogênio de 39 a 42 dias de idade.

\begin{tabular}{cccccc}
\hline & $\begin{array}{c}\text { Consumo de Ração } \\
(\mathbf{g})\end{array}$ & $\begin{array}{c}\text { Ganho de Peso } \\
(\mathbf{g})\end{array}$ & $\begin{array}{c}\text { Conversão } \\
\text { Alimentar } \\
(\mathbf{g} / \mathbf{g})\end{array}$ & $\begin{array}{c}\text { Digestibilidade } \\
\text { da Matéria Seca } \\
(\mathbf{\%})\end{array}$ & $\begin{array}{c}\text { Retenção de } \mathbf{~} \\
(\mathbf{\%})\end{array}$ \\
\hline Nível cálcio & $\mathrm{ns}$ & $\mathrm{ns}$ & $\mathrm{Ns}$ & $*$ & $*$ \\
0,40 & 3268,7 & 1486,7 & 2,2 & 72,5 & 64,2 \\
0,59 & 3013,2 & 1466,4 & 2,1 & 74,2 & 70,6 \\
0,78 & 3033,2 & 1495,0 & 2,0 & 76,8 & 84,6 \\
0,97 & 3076,8 & 1502,0 & 2,1 & 76,6 & 79,1 \\
1,16 & 3101,0 & 1508,8 & 2,1 & 77,0 & 82,0 \\
\hline Fêmeas & $2886,2 \mathrm{a}$ & $1362,2 \mathrm{~b}$ & $2,1 \mathrm{a}$ & $75,1 \mathrm{a}$ & $73,0 \mathrm{a}$ \\
Machos & $3311,0 \mathrm{~b}$ & $1621,4 \mathrm{a}$ & $2,0 \mathrm{a}$ & $75,7 \mathrm{a}$ & $79,1 \mathrm{a}$ \\
\hline Média & 3098,6 & 1491,8 & 2,0811 & 75,4 & 76,1 \\
\hline C. V. (\%) & 5,45 & 3,08 & 5,81 & 1,45 & 12,13 \\
\hline
\end{tabular}

Médias seguidas de letras diferentes na mesma coluna diferem pelo teste $\mathbf{F}(\mathbf{P}<0,058)$

ns - não-significativo $(\mathbf{P}>\mathbf{0 , 0 5})$

* Efeito quadrático $(\mathbf{P}<0,05)$

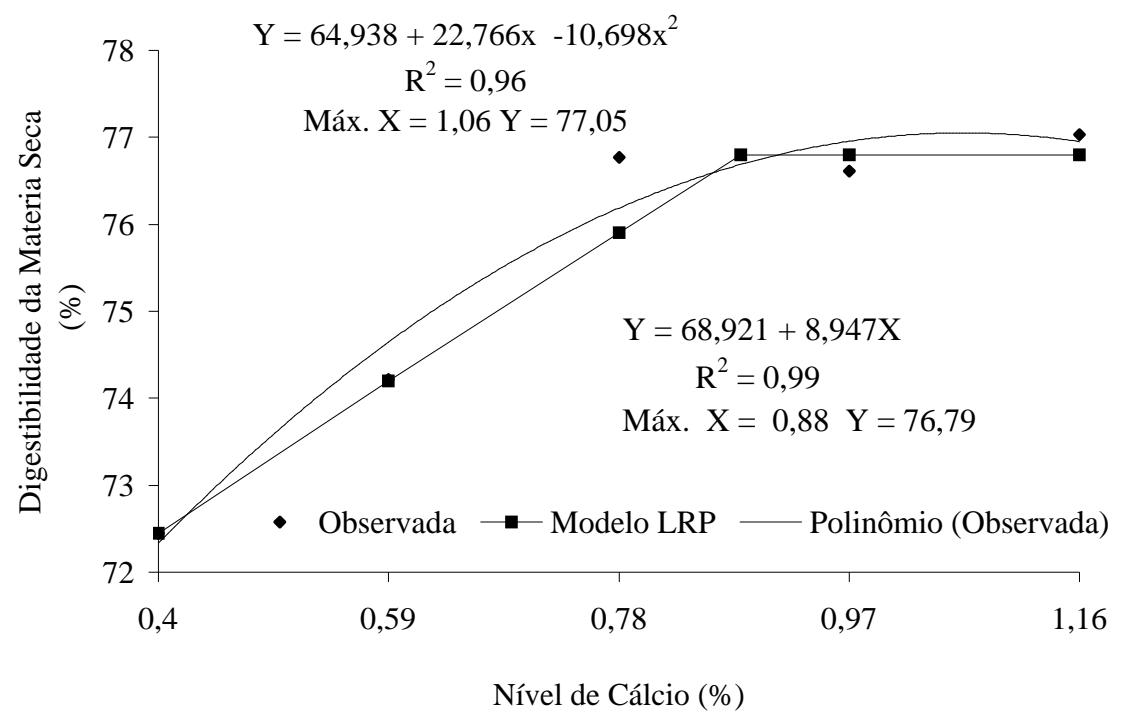

FIGURA 2 - Efeito dos níveis de cálcio da ração sobre a digestibilidade da materia seca da ração de 39 a 42 dias de idade.

Ciênc. agrotec., Lavras. V.27, n.1, p.192-198, jan./fev., 2003 


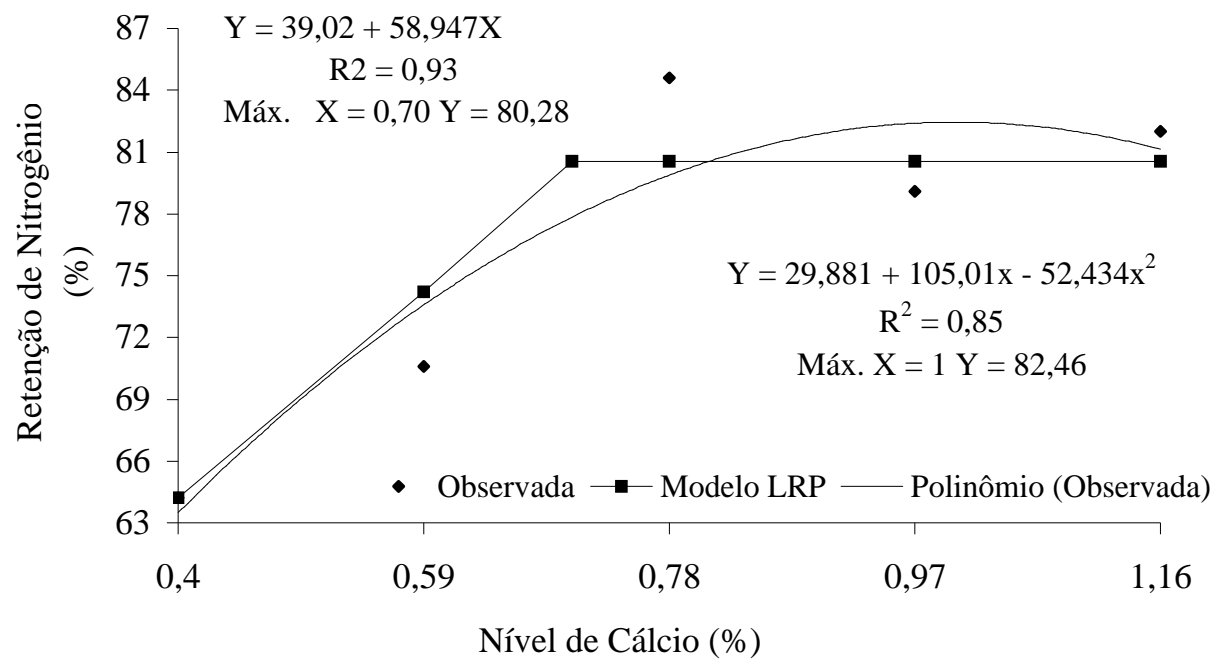

FIGURA 3 - Efeito dos níveis de cálcio da ração sobre a retenção de nitrogênio de 18 a 21 dias de idade.

\section{CONCLUSÕES}

Em rações à base de milho e farelo de soja, para frangos de corte na fase de 22 a 42 dias, suplementadas com fitase, a elevação dos níveis de cálcio não afeta o desempenho e a digestibilidade da matéria seca e a retenção de nitrogênio são reduzidos com baixo nível de cálcio.

Considerando a exigência média de cálcio estimada para as diferentes variáveis analisadas, sugere-se usar $0,62 \%$ de cálcio na ração suplementada com fitase para essa fase.

\section{REFERÊNCIAS BIBLIOGRÁFICAS}

ASSOCIATION OF OFFICIAL ANALYTICAL CHEMIST - AOAC. Official methods of analysis: agricultural chemicals, contaminants and drugs. 15. ed. Washington, 1990. v. 1, 684 p.

BORGES, F. M. O. Utilização de enzimas em dietas avícolas. Cadernos Técnicos da Escola de Veterinária da UFMG, Belo Horizonte, n. 20, p. 5-30, jun. 1997.

BRAGA, J. M. Avaliação de fertilidade do solo (ensaios de campo). Viçosa: UFV, 1983. p. 101. (Publicação, 156).

CABRAL, G. H. Níveis de cálcio em rações para frango de corte. 1999.107 p. Tese (Doutorado em Zootecnia) - Universidade Federal de Viçosa, Viçosa.
EUCLYDES, R. F. Sistema de analises estatísticas e genéticas - SAEG $x$ guia do usuário. Viçosa: UFVCentral de Processamento de Dados, 1993.

FERREIRA, D. F. Sistema de análise estatística para dados balanceados (SISVAR). Lavras: UFLA/DEX, 2000 .

KARUNAJEEWA, H. Effect of some feed additives on the performance of broiler chicks fed diets containing high levels of meat and bone meal. Australian Journal of experimental agriculture and animal husbandry, Cambridge, v. 16, p. 685-690, 1976.

LESKE, K. L.; COON, C. N. A bioassay to determine the effect of phytase on phytate phosphorus hydrolysis and total phosphorus retention of feed ingredients as determined with broilers and laying hens. Poultry Science, Champaign, v. 78, n. 8, p. 1151-1157, Aug. 1999.

ROSTAGNO, H.S. Exigências nutricionais e biodisponibilidade de fósforo para frangos de corte. In: SIMPÓSIO INTERNACIONAL SOBRE NUTRIÇÃO DE AVES, 1998, Campinas. Anais... Campinas: CBNA, 1998. p. 1-27.

ROSTAGNO, H. S.; SILVA, D. J.; COSTA, P. M. A.; FONSECA, J. B.; SOARES, P. R.; PEREIRA, J. A. A.; SILVA, M. A. Composição de alimentos e exigências nutricionais de aves e suínos (Tabelas Brasileiras). Viçosa: UFV, 1994. 59 p.

Ciênc. agrotec., Lavras. V.27, n.1, p.192-198, jan./fev., 2003 
ROSTAGNO, H. S.; TEJEDOR, A. A.; ALBINO, L. F. T; SILVA, J. H. V. Enzyme supplementation of corn and soy bean meal diets improves íleal digestibility of nutrients in broiler chicks. Biotechnology in the feed industry. In: ALLTECH'S ANNUAL SYMPOSIUM, 16, 2000. Proceedings... [S.1.: sn.], 2000. p. 175-182.

SEBASTIAN, S.; TOUCHBURN, S. P.; CHAVEZ, E. R.; LAGUE, P. C. Apparent digestibility of protein and amino acids in broiler chickens fed a corn-soybean diet supplemented with microbial phytase. Poultry Science, Champaign, v. 76, n. 12, p. 1760-1769, Dec. 1997.

SEBASTIAN, S.; TOUCHBURN, S. P.; CHAVEZ, E. R.; LAGUE, P. C. Efficacy of supplemental microbial phytase at different dietary calcium levels on growth performance and mineral utilization of broiler chickens. Poultry Science, Champaign, v. 75, n. 12, p. 15161523, Dec. 1996.
SHAFEY, T. M. Calcium tolerance of growing chickens: effect of ratio of dietary calcium to available phosphorus. Word's Poultry Science Journal, Wageningen, v. 49, n. 1, p. 5-18, Mar. 1993.

SIMONS, P. C. M.; VERSTEEGH, H. A. J.; JONGBLOED, A. W.; KEMME, P. A.; SLUMP, K. D. B. O. S.; WOLTERS, G. E.; BEUDEKER, R. F.; VERSCHOOR, G. J. Improvement of phosphorus availability by microbial phytase in broilers and pigs. British Journal of Nutrition, Cambridge, v. 64, p. 525540, 1990.

SKINNER, J. T., IZAT, L., WALDROUP, P. W. Effects of removal of supplemented calcium and phosphorus from broiler finished diets. Journal Applied Poultry Research, v. 1, p. 42-47, 1992

TEIXEIRA, A. S. Exigências nutricionais de zinco e sua disponibilidade em sulfatos e óxidos de zinco para pintos de corte. 1994.172 p. Tese (Doutorado em Zootecnia) - Universidade Federal do Rio Grande do Sul, Porto Alegre. 